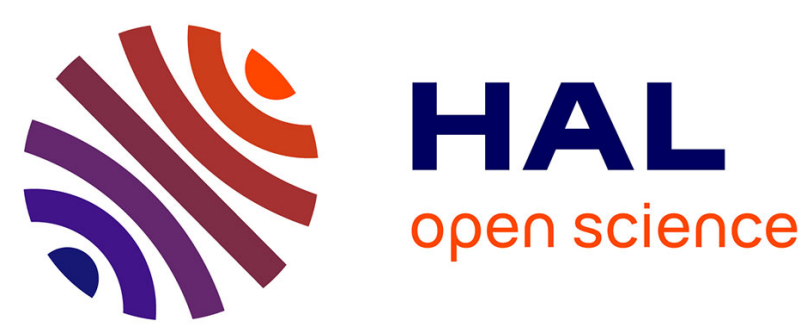

\title{
Elucidation of the thermophilic phenol biodegradation pathway via benzoate during the anaerobic digestion of municipal solid waste
}

\author{
C. Hoyos, M. Hoffmann, A. Guenne, L. Mazéas
}

\section{- To cite this version:}

C. Hoyos, M. Hoffmann, A. Guenne, L. Mazéas. Elucidation of the thermophilic phenol biodegradation pathway via benzoate during the anaerobic digestion of municipal solid waste. Chemosphere, 2014, 97, pp.115-119. 10.1016/j.chemosphere.2013.10.045 . hal-01118472

\section{HAL Id: hal-01118472 \\ https://hal.science/hal-01118472}

Submitted on 19 Feb 2015

HAL is a multi-disciplinary open access archive for the deposit and dissemination of scientific research documents, whether they are published or not. The documents may come from teaching and research institutions in France or abroad, or from public or private research centers.
L'archive ouverte pluridisciplinaire HAL, est destinée au dépôt et à la diffusion de documents scientifiques de niveau recherche, publiés ou non, émanant des établissements d'enseignement et de recherche français ou étrangers, des laboratoires publics ou privés. 


\title{
Elucidation of the thermophilic phenol biodegradation pathway via benzoate during the anaerobic digestion of municipal solid waste.
}

Carolina Hoyos-Hernandez, Marieke Hoffmann, Angeline Guenne, Laurent Mazeas.

Hydrosystems and Bioprocesses Research Unit, National Research Institute of Science and Technology for Environment and Agriculture (IRSTEA), CS 10030, F-92761 Antony, France

\begin{abstract}
Anaerobic digestion makes it possible to valorize municipal solid waste (MSW) into biogas and digestate which are, respectively, a renewable energy source and an organic amendment for soil. Phenols are persistent pollutants present in MSW that can inhibit the anaerobic digestion process and have a toxic effect on microbiota if they are applied to soil together with digestate. It is then important to define the operational conditions of anaerobic digestion which allow the complete degradation of phenol. In this context, the fate of phenol during the anaerobic digestion of MSW at $55{ }^{\circ} \mathrm{C}$ was followed using an isotopic tracing approach $\left({ }^{13} \mathrm{C}_{6}\right.$-phenol) in experimental microcosms with inoculum from an industrial thermophilic anaerobic digester. With this approach, it was possible to demonstrate the complete phenol biodegradation into methane and carbon dioxide via benzoate. Benzoate is known to be a phenol metabolite under mesophilic conditions, but in this study it was found for the first time to be a phenol degradation product at thermophilic temperature.
\end{abstract}

\section{Keywords:}

Municipal solid waste

Anaerobic digestion

Stable carbon isotopic tracing

Phenol biodegradation pathway

Benzoic acid 


\section{Introduction}

Anaerobic digestion (AD) for the treatment of municipal solid waste (MSW) is a process by which microorganisms break down biodegradable material in the absence of oxygen, creating value by transforming the waste into biogas and digestate, which constitute respectively a renewable energy source and an organic amendment for soil.

The MSW can contain phenols which are organic micropollutants that exhibit toxic properties. At high concentrations such compounds can inhibit organic fraction degradation, stopping the process of degradation and the biogas production (Fedorak and Hrudey, 1984; Hernandez and Edyvean, 2008). Moreover, if the degradation of phenol is not complete, the digestate used as fertilizer can contain this pollutant (Angelidaki et al., 2000; Levén et al., 2006) and have adverse effects on soil bacteria, representing a risk for the environment and human health. In this context, it is necessary to make sure that phenol is completely degraded into methane, thus avoiding the methanization inhibition and assuring that digestates contain no phenol when introducing into the soil ecosystem.

Up to now, several studies have shown that phenol degradation at $55^{\circ} \mathrm{C}$ under methanogenic conditions was possible (Karlsson et al., 1999; Fang et al., 2005; Levén et al., 2006; Chen et al., 2008; Limam et al., 2013), but the knowledge regarding the thermophilic phenol metabolic pathway is limited due to the fast degradation rates which hamper metabolite accumulation and pathway elucidation. Nevertheless, today it is generally accepted that thermophilic phenol degradation occurs via caproate (Fang et al., 2005) and not through the benzoic acid pathway, generally used in the mesophilic condition (Knoll and Winter, 1987, 1989; Béchard et al., 1990; Gallert et al., 1991; Karlsson et al., 1999; Levén and Schnürer, 2005; Zhang et al., 2005). This study is focused on the elucidation of the phenol fate and metabolite identification during the AD at 55 ${ }^{\circ} \mathrm{C}$. The elucidation of some intermediate metabolites of phenol degradation will shed light on the ways to improve phenol degradation in bioreactors under thermophilic methanogenic conditions. 


\section{Materials and methods}

\subsection{Chemicals}

The ethyl acetate, methanol, acetone, acetic anhydride, potassium bicarbonate, mercuric chloride and sodium chloride were obtained from Supelco (St. Quentin Fallavier, France). All the solvents and reagents were of analytical degree, and ultrapure water from Milli-Q system (Eschborn, Germany) was used throughout the experiments. The ${ }^{13} \mathrm{C}_{6}$-phenol (99\%) was purchased from EuroIsotope Laboratory (France).

\subsection{Inoculum preparation}

The inoculum used in this study was prepared by the centrifugation of five fractions of $50 \mathrm{~mL}$ of an anaerobic sludge from thermophilic municipal household waste digesters. The centrifugation was carried out at $4{ }^{\circ} \mathrm{C}$ for $10 \mathrm{~min}$ at $8500 \mathrm{rpm}$ (Allegra TM X- $22 \mathrm{R}$ Centrifuge, Beckman Coulter, France). Finally, 2\% (volatile solids) were inoculated in each microcosm for the ${ }^{13} \mathrm{C}_{6}$-phenol study.

\section{$\underline{2.3 \text { Microcosm studies }}$}

Two types of experimental microcosms, with and without MSW, were incubated under thermophilic conditions.

The microcosms containing MSW "waste-incubations" consisted of $5330 \mathrm{~mL}$ glass bottles (Fischer Scientific Bioblock, Illkirch, France) filled with $210 \mathrm{~mL}$ of $\mathrm{NaHCO}_{3}$ buffer solution at $\mathrm{pH}=8.3$ and $10 \mathrm{~g}$ of reconstituted French Solid Waste (MODECOM Composition) (Qu et al., 2009). The inoculum was then simultaneously added to the bottles, which were closed with a screw cap and a septum (Fischer Scientific Bioblock, Illkirch, France), and a nitrogen atmosphere was established (anaerobic treatment). The biogas composition $\left(\mathrm{CH}_{4}\right.$ and $\left.\mathrm{CO}_{2}\right)$ was analyzed immediately after equilibration by connecting the bottle to a gas chromatograph (CP 4900 Micro-GC, Varian, France) equipped with two parallel chromatographic columns coupled to thermal conductivity detectors (TCD). The cumulative biogas production was monitored until it reached stable methanogenesis, after $140 \mathrm{~d} .{ }^{13} \mathrm{C}_{6}$-phenol was then injected into the microcosms. $1.5 \mathrm{mg}$ of phenol was added to each microcosm in order to obtain a concentration of $7200 \mu \mathrm{gL}^{-1}$. Three of the five microcosms were incubated with ${ }^{13} \mathrm{C}_{6}$-phenol. In one of them $300 \mathrm{mg}$ of $\mathrm{HgCl}_{2}$ was diluted in $15 \mathrm{~mL}$ sterilized water and later added to inhibit the biological activity (Tuominen et al., 1994). In another microcosm ${ }^{12} \mathrm{C}_{6^{-}}$ 
phenol was added to monitor the biogas isotopic composition when no enriched substrate was added. No phenol was added to the remaining microcosm.

The second type of microcosm contained no reconstituted MSW "non-waste incubations" but only the inoculum and the biochemical methane potential buffer (BMP) (ISO 11734:1995) in order to evaluate the potential of the inoculum to degrade phenol. This set of microcosms also had 5 incubations, 3 with ${ }^{13} \mathrm{C}_{6^{-}}$ phenol (in one of them $\mathrm{HgCl}_{2}$ was added to inhibit biological activity), one with natural phenol and the last with no phenol. The total volume of these incubations was $40 \mathrm{~mL}$ in $50 \mathrm{~mL}$ glass bottles.

The microcosms were then incubated in the dark at $55{ }^{\circ} \mathrm{C}$ under methanogenic conditions for $60 \mathrm{~d}$ for "wasteincubations" and $236 \mathrm{~d}$ for "non-waste incubations." Liquid samples $(1 \mathrm{~mL})$ were retrieved 3 times a week from the different microcosms in order to analyze the ${ }^{13} \mathrm{C}_{6}$-phenol.

\subsection{Analytical methods}

During the incubation time, the isotopic composition of biogas $\left(\mathrm{CH}_{4}\right.$ and $\left.\mathrm{CO}_{2}\right)$ was measured by $\mathrm{GC}$ IRMS. Moreover, a quantitative analysis of ${ }^{13} \mathrm{C}_{6}$-phenol was performed by GC-MS.

\subsection{1 ${ }^{13} \mathrm{C}_{6}$-phenol}

Phenol concentrations were determined following a published analytical procedure (Limam et al., 2010). Briefly, after the dilution of $100 \mu \mathrm{L}$ of the samples in $2 \mathrm{~mL}$ Milli-Q water, the obtained diluted sample was introduced into a $20 \mathrm{~mL}$ PTFE-capped glass vial, and $0.8 \mathrm{~g}$ of sodium chloride, $0.08 \mathrm{~g} \mathrm{KHCO}_{3}$ and $15 \mu \mathrm{L}$ of acetic anhydride were added. A reaction time of 5 min at $40{ }^{\circ} \mathrm{C}$ was then necessary to obtain a complete derivatization reaction prior to the extraction step. The headspace extraction of derivatized ${ }^{13} \mathrm{C}_{6}$-phenol was performed with a $65 \mu \mathrm{m}$ polydimethylsiloxane-divinylbenzene-solid phase microextraction (SPME) fiber at $40{ }^{\circ} \mathrm{C}$, with a $500 \mathrm{rpm}$ for $30 \mathrm{~min}$. Each head-space extract was analyzed with a GC-MS. MS was operated in the electron impact ionization mode with a scan range of $m / z 50-400$ at 3.88 scans s$^{-1}$. The quantification was performed on the selected ion monitoring mode. Quantification ions were $m / z 100$ for ${ }^{13} \mathrm{C}_{6}$-phenol and $\mathrm{m} / z 99$ for ${ }^{12} \mathrm{C}_{6}$-phenol. Xcalibur Software from Thermo Fisher Scientific was used for online data acquisition and processing. 


\section{$\underline{2.4 .2{ }^{13} \mathrm{C}_{6} \text {-phenol metabolites }}$}

${ }^{13} \mathrm{C}_{6}$-Phenol metabolites were obtained by a liquid-liquid extraction of $500 \mu \mathrm{L}$ microcosm liquid phase. The $\mathrm{pH}$ of each sample was maintained at a value above 12 for $30 \mathrm{~min}$ by the stepwise addition of $1 \mathrm{~N}$ $\mathrm{NaOH}$ to hydrolyze putative thioester bonds. Each sample was then acidified to a pH below 2 with $12 \mathrm{~N} \mathrm{HCl}$. The samples were then extracted three times with $2.5 \mathrm{~mL}$ of ethyl acetate. The three fractions of ethyl acetate extracts were combined, dried through anhydrous sodium sulfate, and then concentrated to a volume of 500 $\mu \mathrm{L}$ under a stream of nitrogen gas. The ethyl acetate extract was then derivatized with N,O-bis(trimethylsilyl)trifluoroacetamide. Each concentrated and derivatized extract was analyzed with the GC-IRMS system. Chromatographic conditions were the same as described above in ${ }^{13} \mathrm{C}_{6}$-phenol section. The elucidation of the chemical structure of the ${ }^{13} \mathrm{C}$-labeled metabolites identified by the GC-IRMS analysis was carried out by a GC-MS using the same chromatographic conditions as for the GC-IRMS analysis.

\subsubsection{Biogas isotopic composition}

The biogas analysis of the $\mathrm{CO}_{2}$ and $\mathrm{CH}_{4}$ isotopic composition of carbon was carried out by injecting 10 $\mu \mathrm{L}$ of the headspace gas from each incubation, using a $100 \mu \mathrm{L}$ Pressure-Lock gas tight syringe in a GC-IRMS system (Thermo Fisher Scientific, France). The GC-IRMS system consisted of a Trace GC Ultra attached to a Delta $\mathrm{V}$ plus isotope ratio mass spectrometer via a Finnigan GC combustion III unit. Typical $\delta^{13} \mathrm{C}$ uncertainties, quantified by repeated measurements of a referential $\mathrm{CH}_{4}$ and $\mathrm{CO}_{2}$ mixture of a known isotopic composition, were $\pm 0.1 \%$ for both gases.

\section{Results and discussion}

$\underline{3.1 \text { Anaerobic biodegradation of }{ }^{13} \mathrm{C}_{6}} \underline{\text { phenol under thermophilic conditions - incubations without solid waste }}$ (non-waste incubations)

In such incubations only the inoculum was present in the incubation medium. Hence, it was possible to measure the potential of a thermophilic MSW biodigester inoculum to degrade phenol.

The remaining ${ }^{13} \mathrm{C}_{6}$-phenol concentration over time is represented in Fig. 1a. Firstly, it was observed that phenol concentration for the abiotic incubation "Abiotic13C," remained stable over time without any diminution, whereas in the biotic ones the concentration decreases. This demonstrates that in the incubations 
the biological activity is responsible for phenol degradation. This result is in agreement with previous studies (Limam et al., 2013) where phenol biodegradation was observed at $55{ }^{\circ} \mathrm{C}$ but diverges from certain other studies (Levén and Schnürer, 2005, 2010) where an inhibition of phenol degradation at this specific temperature was observed.

In the biotic incubations, $200 \mathrm{~d}$ were needed to reduce the phenol concentration to less than $1 \%$. Two of them, "Biotic13CB" and "Biotic12C" in which ${ }^{13} \mathrm{C}$-phenol and ${ }^{12} \mathrm{C}$-phenol were added respectively, presented a lag-phase during the first $34 \mathrm{~d}$ tailed by a degradation phase. In contrast, the "Biotic13CA" incubation, presented a rapid phenol concentration decrease during the first $6 \mathrm{~d}$ without any lag-phase followed by a progressive diminution from that day until the end.

Thanks to the isotopic approach, it was also possible to determine if phenol $\left({ }^{13} \mathrm{C}\right.$ enriched) was totally degraded to methane and carbon dioxide since its ${ }^{13} \mathrm{C}$ enrichments in the headspace had been monitored (Fig. $1 \mathrm{~b}$ and $1 \mathrm{c})$. Methane and carbon dioxide isotopic compositions $\left(\delta^{13} \mathrm{C}\right)$ expressed in \%o showed the enrichment of ${ }^{13} \mathrm{C}$ in $\mathrm{CH}_{4}$ or $\mathrm{CO}_{2}$ produced during ${ }^{13} \mathrm{C}_{6}$-phenol biodegradation. An evolution toward positive isotopic composition means that enriched methane and carbon dioxide was produced from ${ }^{13} \mathrm{C}$-phenol degradation. The comparison between isotopic compositions measured in ${ }^{13} \mathrm{C}$-phenol incubation and the natural incubation gave information regarding the fate of phenol. Indeed, for ${ }^{13} \mathrm{C}$ biotic incubations positive isotopic compositions were observed whereas those values were negative for the natural phenol incubations. Hence, this clearly demonstrates that ${ }^{13} \mathrm{C}$-phenol was degraded to methane and carbon dioxide in these thermophilic incubations.

The ${ }^{13} \mathrm{C}$ enrichment trends were different in the two $13 \mathrm{C}$ biotic incubations. Indeed, the biotic incubation "Biotic13CA," which had fast ${ }^{13} \mathrm{C}_{6}$-phenol degradation during the first six days, had instantaneous biogas enrichment during the same period. On the opposite, the incubation "Biotic13CB" did not present gas enrichment directly after day 34 when its degradation began, but its enrichment began from day 83 when $60 \%$ of the phenol had already been degraded (Fig. 1). Therefore, during "Biotic13CA" incubation, the phenol biodegradation apparently led to an instantaneous $\mathrm{CH}_{4}$ and $\mathrm{CO}_{2}$ production as previously observed (Limam et al., 2013), but for "Biotic13CB" incubation, the enrichment presents a gap between the phenol degradation 
and gas enrichment. This gap between gas production and phenol degradation was probably a lapse of time during which metabolites were being accumulated.

3.2 Anaerobic biodegradation of ${ }^{13} \mathrm{C}_{6}-$ phenol under thermophilic conditions - incubations with reconstituted French municipal solid waste (waste incubations)

In these incubations the inoculum and reconstituted French wastes (Modecom) were introduced into the incubations in order to be closer to the conditions of real waste biodigesters.

As for non-waste incubations, the phenol degradation in these experiments was due to biological activity. Indeed, the biotic incubations showed a decrease in phenol concentration, whereas the abiotic did not (Fig. 2a). It is very important to note that the degradation time for waste-incubations was 5 times faster (40 d) than for no-waste incubations (200 d). Moreover, no lag-phase was evidenced and the degradation kinetics were more repeatable. The improvement of phenol degradation rates could be due to the fact that waste degradation and methane production stabilization in these incubations were reached before the ${ }^{13} \mathrm{C}_{6}$-phenol was added, which could promote the development of different communities of microorganisms such as phenol degraders, among others. Furthermore, the nutrients coming from the waste could also help the biodegradation of phenol via co-metabolism.

The isotopic compositions of $\mathrm{CH}_{4}$ and $\mathrm{CO}_{2}$ during waste incubations are represented in Figs. 2b-2c. They clearly prove that phenol was totally degraded to $\mathrm{CO}_{2}$ and $\mathrm{CH}_{4}$ since non-natural isotopic compositions for those two gases were measured in the headspace of biotic ${ }^{13} \mathrm{C}$ incubations contrary to what was observed for the ${ }^{12} \mathrm{C}$ biotic experiment. In these incubations a gap between phenol degradation and the gas production was evident. In fact, it was possible to note that the isotopic composition of methane started to increase only when $80 \%$ of the phenol had already been degraded. It seems very likely that this gap was the lapse of time during which phenol intermediates were being accumulated before methanogenesis took place.

\section{$\underline{3.3 \text { Metabolic pathway under thermophilic conditions }}$}

In order to identify phenol degradation products for non-waste and waste-incubations, some GCIRMS analyses of the liquid phase were performed. Using this approach each product exhibiting non-natural isotopic composition was identified as a metabolite. 
In the non-waste "Biotic13CA" incubation no enriched compounds other than phenol were detected. As the degradation of phenol to $\mathrm{CO}_{2}$ and $\mathrm{CH}_{4}$ seemed to be instantaneous during this incubation, it seems possible that no accumulation of degradation product occurred during this incubation, as previously suggested (Limam et al., 2013). In this case it was impossible to identify the phenol degradation pathways.

During all the other ${ }^{13} \mathrm{C}$ biotic incubations, both waste and non-waste incubations, the presence of a ${ }^{13} \mathrm{C}$ enriched compound other than phenol was observed (Fig. 3). Indeed, non-natural 45/44 isotopic ratios were observed on the figures for the peak present at $1320 \mathrm{~s}$. Since the natural configuration method was used for these analyses, the amplification of the $m / z 45$ signal was 100 time higher than the $m / z 44$ signal. Hence, for compounds exhibiting a natural isotopic composition the $45 / 44$ ratio signal should have been around 1 . In the incubations, the $45 / 44$ ratio for the peak at 1320 s exhibited much higher values than 1 , showing that those peaks corresponded to ${ }^{13} \mathrm{C}_{6}$-phenol metabolites. The ${ }^{13} \mathrm{C}$ percentage of these compounds for both incubations was around $30 \%$, which confirmed that the compounds were not natural since natural compounds contain only $1.1 \%$ of ${ }^{13} \mathrm{C}$.

The identification of their chemical structure was performed by GC-MS analysis. The obtained mass spectrum is given on Fig. 4b. The GC-MS analysis confirmed that the peak present around $1320 \mathrm{~s}$ in both incubations corresponds to the trimethylsilyl derivatives (TMS) of ${ }^{13} \mathrm{C}_{6}$-benzoic acid. This identification was made using the comparison between the library mass spectra of TMS ${ }^{12} \mathrm{C}$ benzoate and TMS ${ }^{13} \mathrm{C}_{6}$-benzoic acid (Fig. 4a-4b respectively) which showed a shift of 6 atomic mass units for all ions, which seems evident since 6 carbons are contained within the benzoic acid ring.

Previous research points to the fact that under thermophilic conditions phenol is degraded via caproic acid (Fang et al., 2005). Nevertheless, ${ }^{13} \mathrm{C}_{6}$-caproic acid was not detected but rather ${ }^{12} \mathrm{C}$ (data not shown). In light of these results, it is clear that phenol degradation can occur via benzoic acid under thermophilic conditions as it does under mesophilic conditions. To our knowledge, this is the first time that ${ }^{13} \mathrm{C}_{6}$-Benzoic acid has been identified as a metabolite in the thermophilic phenol pathway to methane. It is important to note that this finding does not exclude other possible pathways. 


\section{Conclusions}

This study proves that phenol degradation into methane is totally supported by the microorganism under thermophilic conditions at $55{ }^{\circ} \mathrm{C}$ during the anaerobic degradation of municipal solid waste. Also, this is the first time that benzoate has been identified as a metabolite of phenol under thermophilic $\left(55^{\circ} \mathrm{C}\right)$ methanogenic conditions. This finding opens a new way to understand phenol degradation in municipal solid waste digesters under thermophilic conditions since some similarities can be shared with mesophilic phenol degradation.

\section{Acknowledgements}

We gratefully acknowledge the contribution of the whole HBAN IRSTEA team, and the financial support of the R2DS research programme of the Region Ile de France.

\section{References}

Angelidaki, I., Mogensen, a S., Ahring, B.K., 2000. Degradation of organic contaminants found in organic waste. Biodegradation 11, 377-83.

Béchard, G., Bisaillon, J.-G., Beaudet, R., Sylvestre, M., 1990. Degradation of phenol by a bacterial consortium under methanogenic conditions. Can. J. Microbiol. 36, 573-578.

Chen, C.-L., Wu, J.-H., Liu, W.-T., 2008. Identification of important microbial populations in the mesophilic and thermophilic phenol-degrading methanogenic consortia. Water Res. 42, 1963-76.

Fang, H.H.P., Liang, D.W., Zhang, T., Liu, Y., 2005. Anaerobic treatment of phenol in wastewater under thermophilic condition. Water Res. 40, 427-34.

Fedorak, P.M., Hrudey, S.E., 1984. The effects of phenol and some alkyl phenolics on batch anaerobic methanogenesis. Water Res. 18, 361-367.

Gallert, C., Knoll, G., Winter, J., 1991. Anaerobic carboxylation of phenol to benzoate: use of deuterated phenols revealed carboxylation exclusively in the C4-position. Appl. Microbiol. Biotechnol. 36, 124129.

Hernandez, J.E., Edyvean, R.G.J., 2008. Inhibition of biogas production and biodegradability by substituted phenolic compounds in anaerobic sludge. J. Hazard. Mater. 160, 20-28.

ISO, 11734:1995 Water Quality - Evaluation of the "Ultimate" Anaerobic Biodegradability of Organic Compounds in Digested Sludge -Method by Measurement of the Biogas Production, EN ISO 11734:1995, 1996. 
Karlsson, A., Ejlertsson, J., Nezirevic, D., Svensson, B.H., 1999. Degradation of phenol under meso- and thermophilic, anaerobic conditions. Anaerobe 5, 25-35.

Knoll, G., Winter, J., 1987. Anaerobic degradation of phenol in sewage sludge. Appl. Microbiol. Biotechnol. $25,384-391$.

Knoll, G., Winter, J., 1989. Degradation of phenol via carboxylation to benzoate by a defined, obligate syntrophic consortium of anaerobic bacteria. Appl. Microbiol. Biotechnol. 30, 318-324.

Levén, L., Nyberg, K., Korkea-Aho, L., Schnürer, A., 2006. Phenols in anaerobic digestion processes and inhibition of ammonia oxidising bacteria (AOB) in soil. Sci. Total Environ. 364, 229-38.

Levén, L., Schnürer, A., 2005. Effects of temperature on biological degradation of phenols, benzoates and phthalates under methanogenic conditions. Int. Biodeterior. Biodegradation 55, 153-160.

Levén, L., Schnürer, A., 2010. Molecular characterisation of two anaerobic phenol-degrading enrichment cultures. Int. biodeter. Biodegr. 64, 427-433.

Limam, I., Guenne, A., Ridha Driss, M., Mazeas, L., 2010. Simultaneous determination of phenol, methylphenols, chlorophenols and bisphenol-A by headspace solid-phase microextraction-gas chromatography-mass spectrometry in water samples and industrial effluents. Int. J. Environ. An. Ch. 90 .

Limam, I., Mezni, M., Guenne, A., Madigou, C., Driss, M.R., Bouchez, T., Mazéas, L., 2013. Evaluation of biodegradability of phenol and bisphenol A during mesophilic and thermophilic municipal solid waste anaerobic digestion using ${ }^{13} \mathrm{C}$-labeled contaminants. Chemosphere 90, 512-20.

Qu, X., Vavilin, V.A., Mazéas, L., Lemunier, M., Duquennoi, C., He, P.-J., Bouchez, T., 2009. Anaerobic biodegradation of cellulosic material: batch experiments and modelling based on isotopic data and focusing on aceticlastic and non-aceticlastic methanogenesis. Waste Manag. 29, 1828-37.

Tuominen, L., Kairesalo, T., Hartikainen, H., 1994. Comparison of methods for inhibiting bacterial activity in sediment. Appl. Environ. Microbiol. 60, 3454-3457.

Zhang, T., Ke, S.Z., Liu, Y., Fang, H.P., 2005. Microbial characteristics of a methanogenic phenol-degrading sludge. Water Sci. Technol. 52 (1-2), 73-78. 